\title{
OS LIMITES DO ARGUMENTO DO RELATIVISMO NA FILOSOFIA DO DIREITO DE ALEXY E O POSITIVISMO DE HART
}

\author{
THE LIMITS OF THE ARGUMENT OF RELATIVISM IN THE ALEXY'S LEGAL PHILOSOPHY \\ AND THE HART'S POSITIVISM
}

Wesley Felipe de Oliveira

\begin{abstract}
Doutor e Mestre em Filosofia pela Universidade Federal de Santa Catarina (UFSC); Especialista em Educação e Filosofia pelo Instituo Tecnológico e Educacional (ITECNE); Bacharel e Licenciatura em Filosofia pela Universidade Estadual do Oeste do Paraná (UNIOESTE); Professor substituto na Universidade Federal de Santa Catarina (UFSC).

Email: wesley.filosofia@ hotmail.com
\end{abstract}

Cinthia Berwanger Pereira

Mestre em Filosofia pela Universidade Federal de Santa Catarina (UFSC); Licenciatura em Filosofia pela Universidade Federal de Santa Catarina (UFSC).

Email: cinthiaberwan@hotmail.com

Recebido em: 18/06/2018

Aprovado em: 15/04/2019

RESUMO: O cognitivismo e o não-cognitivismo em ética é um tema pouco tratado na filosofia do direito. O objetivo deste trabalho é desenvolver um estudo sobre este tema e reconstruir o argumento onde Robert Alexy afirma ter encontrado um valor aceito universalmente e capaz de fundamentar a moral. De acordo com Alexy, a descoberta deste valor culminaria na extinção do positivismo jurídico. Pretende-se, portanto, delimitar a teoria de Alexy, visando a reconstrução de seu argumento de que se pudesse haver uma moral fundamentada absolutamente, o positivismo teria sido refutado. Para discorrermos sobre o positivismo, usaremos o trabalho de H. L. A. Hart, no qual são detalhados tipos de positivismos e, assim, demonstraremos que o positivismo não nega que o Direito possa ter fundamentos morais. Será analisado, então, quais as consequências que esta obra de Hart traria para a teoria de Alexy.

Palavras-Chave: Relativismo; Positivismo; Cognitivismo; Não-cognitivismo; Alexy; Hart.

ABSTRACT: Cognitivism and non-cognitivism in ethics is a not too much discussed theme in the philosophy of law. The objective of this work is to develop a study on this theme and to reconstruct the argument where Robert Alexy claims to have found a universally accepted value able to justify morality. According to Alexy, the discovery of this value would culminate in the extinction of legal positivism. It is intended, therefore, to delimit Alexy's theory, in order to reconstruct his argument that if there could be a morality justified absolutely, positivism would have been refuted. To discuss positivism, we will work with H. L. A. Hart's thesis, in which types of positivism are detailed, and 
thus we will show that positivism does not deny that law can have moral foundations. It will be analyzed, then, the consequences that this work of Hart would bring to the theory of Alexy.

Keywords: Relativism; Positivism; Cognitivism; Non-cognitivism; Alexy; Hart.

SUMÁRIO: Introdução; 1 Cognitivismo e não-cognitivismo em ética; 2 Alexy e a refutação do positivismo; 3 Hart e os cinco tipos distintos de positivismo; Conclusão; Referências.

\section{INTRODUÇÃO}

O presente artigo possui uma parte analítica e uma parte crítica. Primeiramente, apresentaremos a questão do cognitivismo e o não-cognitivismo em ética, expondo as bases para adentrarmos no tema do positivismo jurídico. Discutiremos, então, a posição de Alexy de que o positivismo pressupõe o não-cognitivismo e, desta forma, ao provar que há um valor fundamental que pode ser provado, então a vertente positivista teria sido refutada.

Em um segundo momento, a partir do que foi exposto acerca do cognitivismo e do nãocognitivismo em ética, será analisado o argumento de Robert Alexy no qual, com auxílio de estudos de Joseph Raz, Hans Kelsen, Soren Kierkegaard, entre outros, afirma ter encontrado um valor universal para o Direito. Este valor, segundo o autor, seria o da dignidade humana e, segundo Alexy, atribuir dignidade humana a alguém é reconhecer seus direitos humanos e, tendo este sido encontrado, isso proporcionaria, para Alexy, uma moral fundamentada de modo absoluto, e, sendo assim, através da aplicação da fórmula de Radbruch, o positivismo jurídico estaria refutado.

Após a apresentação da tese de Alexy, propomo-nos, neste artigo, desenvolver a ideia de Hart segundo a qual existem distintas variações do positivismo, e que há teóricos que aceitam a conexão entre Direito e Moral. Hart aponta existir cinco tipos de positivismo, cada um com qualidades distintas. Um destes tipos possui a característica que afirma que o positivismo não pressupõe o não-cognitivismo em ética. Isso se opõe a ideia de Alexy de que o positivismo jurídico estaria refutado ao ser encontrado um valor universal que fundamentaria o Direito. Contraporemos, ao final, a ideia de Alexy e de Hart, apresentando as conclusões advindas destes estudos, expressando uma análise sobre o conceito de positivismo jurídico e identificando os limites do direito no âmbito da filosofia do direito de Alexy.

\section{COGNITIVISMO E NÃO-COGNITIVISMO EM ÉTICA}

A primeira grande divisão das correntes metaéticas é entre o cognitivismo e o nãocognitivismo em ética. O cognitivismo afirma a possibilidade de se conhecer a verdade no campo da ética e defende a possibilidade de se afirmar serem verdadeiras ou falsas proposições referentes à moral. A razão, no cognitivismo, desempenha um papel fundamental de guia no julgamento do que é correto ou incorreto moralmente. Jürgen Habermas é um dos princípais representantes da corrente cognitivista.

O não-cognitivismo (também conhecido como anti-realismo), ao contrário do cognitivismo, afirma não ser possível conhecer a verdade no campo da ética e, portanto, não seria possível realizar afirmações no que se refere à moral. A razão, no não-cognitivismo, desempenha um papel meramente instrumental, não sendo capaz de nos dizer o que é correto ou incorreto moralmente. Hans Kelsen é o principal teórico do não-cognitivismo. 
Alexy considera que ser um positivista implica, necessariamente, em ser um nãocognitivista, pois, para Alexy um positivista separa o direito da moral. Alexy alega que se há um valor moral que possa ser fundamentado o positivismo estaria, desta maneira, refutado. Porém, Hart, em seu artigo Positivism and the Separation of Law and Morals, de 1955, alega que ser um cognitivista em ética não implica em ser um positivista ou não-positivista no direito. As consequências destas duas alegações, de Alexy e Hart, e suas implicações, serão vistas no decorrer deste artigo.

Tendo introduzido o tema, daremos, então, sequência ao nosso trabalho apresentando a teoria de Alexy e seus argumentos.

\section{ALEXY E A REFUTAÇÃO DO POSITIVISMO}

Em seu artigo Law, Morality, and the Existence of Human Rights, de 2012, Alexy desenvolve um argumento a partir do argumento do relativismo. $\mathrm{O}$ autor afirma que o argumento do relativismo desempenha um papel crucial na questão entre o positivismo e o não-positivismo. $\mathrm{O}$ argumento do relativismo trabalhado por Hans Kelsen, alega Alexy, sustenta que uma ligação entre direito e moral possui como pressuposto a existência de elementos morais absolutos, e estes elementos podem ser objetivos ou necessários. Este argumento sustenta ainda que nenhum desses elementos morais, sejam eles absolutos, objetivos ou ainda necessários existe. A partir destas afirmativas, Alexy desenvolve sua própria teoria na qual ele sustenta que elementos morais absolutos, objetivos ou necessários existem. Alexy considera que tais elementos morais existem para que os direitos humanos existam, e os direitos humanos só existem porque são justificáveis.

Para Kelsen, "a teoria de que um sistema social imoral não é direito pressupõe uma moral absoluta, ou seja, uma moral que seja válida em qualquer lugar e em todos os tempos"1 (KELSEN apud ALEXY, 2012, p. 1, tradução nossa). Esta moral, segundo Alexy, deve ser dada a priori. Ele afirma que não é possível um "elemento comum", isto é, um fato qualquer dado não é o bastante para ser considerado como base de uma ligação entre direito e moral. Kelsen alega que mesmo se tal elemento existisse, o que ele próprio rejeita, este não criaria "o que tem que ser concebido como bom e mau, justo e injusto, em todas as circunstâncias"2 (ALEXY, 2012, p. 1, tradução nossa). Desta forma, segundo Kelsen, o positivismo está atrelado ao problema de haver evidências que comprovem se existem ou não elementos morais absolutos ou necessários, como prefere denominar Alexy.

$\mathrm{O}$ argumento de Alexy divide-se, então, em duas partes principais. Primeiro, ele trabalha a relação entre o problema do positivismo e o problema da existência e, em segundo, utilizando a teoria dos direitos humanos, apresenta a solução para o problema da existência.

Alexy inicia a defesa de sua teoria a partir da relação que há entre o problema do positivismo e o problema de existência e, havendo diferentes teorias acerca da relação estabelecida entre moral e direito, alguns esclarecimentos com relação ao conceito de positivismo e não-positivismo se fazem necessários.

\section{Três elementos e duas dimensões}

\footnotetext{
1 “[...] the theses 'that an immoral social system is not law presupposes an absolute morality, that is to say, a morality that is valid everywhere and at all times."”

2 "[...] what has to be conceived as good and bad, just and unjust under all circumstances."
} 
Para Alexy, as discussões relacionadas ao positivismo resumem-se a três elementos: primeiro, a emissão de autoridade; segundo, a eficácia social; e, terceiro, a correção de conteúdo que inclui a correção moral. Destes três, apenas o primeiro e o segundo elemento fazem parte da teoria positivista. Alexy acrescenta que ao reconhecerem apenas dois dos três elementos citados, os positivistas apoiariam, então, a tese da separabilidade. Consequentemente, os não-positivistas apoiariam a tese da conexão, pois consideram todos os três elementos citados, defendendo, desta forma, a tese de que os elementos morais estão incluídos no conceito de direito. Sobre esta diferenciação dos três elementos e a distinção feita pelas teorias positivistas e as teorias nãopositivistas, Alexy acrescenta:

Esta distinção entre e dentre estes três elementos pode ser desenvolvida mais à tese de dupla natureza (Alexy, 2010, p. 167). Essa tese apresenta a alegação de que o direito compreende, necessariamente, tanto uma dimensão real ou factual quanto uma dimensão ideal ou crítica. A dimensão real é representada pelos elementos de emissão de autoridade e eficácia social, ao passo que a dimensão ideal encontra expressão no elemento de correção moral. Emissão de autoridade e eficácia social são fatos sociais. Se alguém afirma que os fatos sociais só podem determinar o que é e o que não é exigido pelo direito, essa afirmação equivale à aprovação de um conceito positivista de direito. Uma vez que a correção moral é adicionada como um terceiro elemento necessário, um conceito nãopositivista de direito emerge. Assim, a tese de dupla natureza implica o não-positivismo ${ }^{3}$ (ALEXY, 2012, p. 3, tradução nossa).

\section{Duas formas de positivismo}

O positivismo exclusivo (defendido por Kelsen) e o positivismo inclusivo (defendido por Hart) são duas significativas divisões do positivismo que estão relacionadas ao debate entre direito e moral. Como principal defensor do positivismo exclusivo temos Joseph Raz, que afirma que a moral é, necessariamente, excluída do conceito de direito (RAZ, 2009, p. 47). Alexy elabora a seguinte fórmula para demonstrar como se dá o positivismo exclusivo: se "I" representa "o direito inclui a moral', então o positivismo exclusivo pode ser expresso através do operador de necessidade

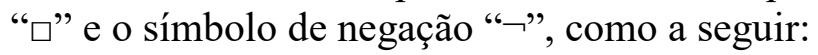

(1) $\square \neg \mathrm{I}$

Como pode ser visto acima, o positivismo exclusivo expressa o oposto do que expressa o não-positivismo, onde temos que a moral é, necessariamente, incluída no conceito de direito. $\mathrm{O}$ não-positivismo pode ser expresso da seguinte forma:

(2) $\square \mathrm{I}$

O positivismo inclusivo tem como um de seus principais defensores Jules Coleman e Hart (considerado por muitos como positivista inclusivo), e afirma que a moral não é nem necessariamente excluída e nem necessariamente incluída, ou seja, rejeita tanto o positivismo exclusivo quanto o não-positivismo. Coleman afirma que a exclusão ou inclusão da moral no positivismo inclusivo ocorre de acordo com o que é convencional (ALEXY, 2012, p. 4). O positivismo inclusivo pode ser representado na seguinte fórmula:

\footnotetext{
3"This distinction between and among these three elements can be developed further into the dual-nature thesis (Alexy 2012, 167). This thesis sets out the claim that law necessarily comprises both a real or factual dimension and an ideal or critical one. The factual dimension is represented by the elements of authoritative issuance and social efficacy, whereas the ideal dimension finds its expression in the element of moral correctness. Authoritative issuance and social efficacy are social facts. If one claims that social facts alone can determine what is and what is not required by law, this claim amounts to the endorsement of a positivistic concept of law. Once moral correctness is added as a necessary third element, a non-positivistic concept of law emerges. Thus, the dual-nature thesis implies non-positivism."
} 


\section{(3) $\neg \square \neg \mathrm{I} \& \neg \square \mathrm{I}$}

Estas três posições encontram-se em uma posição de oposição às outras. Cada uma das três exclui as demais sem que isso decorra da negação de qualquer uma das outras. Alexy explica (ALEXY, 2012, p. 4) que a dinâmica destas três posições pode ser expressa através de uma tríade que esgota o espaço lógico do problema do positivismo na medida em que a necessidade da inclusão ou da exclusão da moral no conceito de direito está em causa:

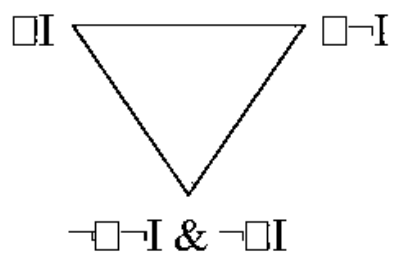

Alexy denomina esta tríade de "tríade necessária”.

\section{Três formas de não-positivismo}

O não-positivismo apresenta dentro dele próprio diferenças tão significativas quanto as diferenças apresentadas dentro do próprio positivismo. Todas estas vertentes de positivismo e nãopositivismo são fundamentais no debate acerca da natureza jurídica. Ao se tratar do argumento do relativismo defendido por Kelsen, as diferenças dentro do não-positivismo são ainda mais relevantes. Alexy considera que:

As diferenças dentro do não-positivismo que são relevantes aqui derivam dos diferentes efeitos sobre a validade jurídica que podem ser atribuídos a defeitos morais. $\mathrm{O}$ nãopositivismo pode determinar o efeito sobre a validade jurídica que decorre de defeitos morais ou deméritos de ter̂s maneiras diferentes. Pode ser o caso que a validade jurídica se perde em todos os casos, ou pode ser o caso que a validade jurídica se perde em alguns casos e em outros não, ou, finalmente, pode ser o caso que a validade jurídica de nenhuma maneira é afetada ${ }^{4}$ (ALEXY, 2012, p. 4-5, tradução nossa).

O primeiro caso é a versão considerada a mais radical do não-positivismo. Esta versão denominada de não-positivismo exclusivo determina que devem ser considerados todos os defeitos morais, todas as injustiças e os lucros de validade jurídicas. O conceito clássico que caracteriza esta versão é uma declaração de Agostinho, que afirma o seguinte: "o direito não é apenas o que me parece ser um direito" 5 (AGOSTINHO apud ALEXY, 2012, p. 5, tradução nossa). Como afirma Alexy, o não-positivismo exclusivo defende a ideia que toda falha moral é tida como excludente dos fatos sociais a partir das fontes de validade jurídica.

Contudo, Alexy afirma que esta versão do não-positivismo, (o não-positivismo exclusivo), não será defendido por ele, pois, este tipo de não-positivismo dá pouquíssimo peso à dimensão factual do direito. Por se tratar do tipo mais forte de não-positivismo, Alexy acredita que isso

\footnotetext{
4“"The differences within non-positivism that are relevant here stem from the different effects on legal validity that can be attributed to moral defects. Non-positivism can determine the effect on legal validity that stems from moral defects or demerits in three different ways. It might be the case that legal validity is lost in all cases, or it might be the case that legal validity is lost in some cases and not in others, or, finally, it might be the case that legal validity is affected in no way at all."

5 “[...] a law that is not just would not seem to me to be a law."
} 
proporciona uma maior vulnerabilidade à tese. A presente natureza controversa de diversas questões morais faz com que a crítica de Kelsen contra o não-positivismo torne-se uma crítica bem sucedido ao não-positivismo exclusivo. Porém, Alexy faz uma ressalva ao ataque de Kelsen. Para Alexy, essa crítica de Kelsen ao não-positivismo resultou em uma crítica bem sucedido apenas no que se refere ao não-positivismo exclusivo, no entanto, acrescenta Alexy, refutar o não-positivismo exclusivo não é, de maneira nenhuma, refutar o não-positivismo, pois existem formas de nãopositivismo que suportam o argumento do relativismo.

O não-positivismo super-inclusivo é considerado a contrapartida radical do não-positivismo exclusivo. O não-positivismo super-inclusivo afirma que os defeitos morais de maneira alguma afetam a validade jurídica. Essa característica faz com que haja, à primeira vista, uma semelhança com o positivismo, porém, esta "semelhança" torna-se equivocada ao notar-se que existem dois tipos de conexão entre direito e moral: uma conexão de classificação e uma conexão de qualificação (ALEXY, 2002, p. 26). Ambos os tipos diferenciam-se um do outro através das consequências dos defeitos morais. A consequência dos defeitos morais em uma conexão de classificação é a perda da validade jurídica ou do caráter legal. Já a consequência dos defeitos morais em uma conexão de qualificação não traz como resultado a ruína da validade jurídica ou do caráter legal. Alexy afirma:

A combinação do postulado de Kant da "submissão (in)condicional" (Kant, 1996, p. 506) para o direito positivo com a ideia de submissão necessária do direito positivo ao direito não-positivo pode ser lida como uma versão do não-positivismo super-inclusivo (ver: Alexy, 2008ª , p. 288-9, 2010, p. 174). O mesmo se aplica à tese de Aquino que um direito tirânico é direito, mas "não direito naturalmente"4, ou como John Finnis refere "não direito no sentido focal do termo "direito"” (Finnis, 1980, p. 364). ${ }^{6}$ (ALEXY, 2012, p. 6, tradução nossa).

O não-positivismo exclusivo foi descartado pelo fato de não dar peso suficiente à dimensão factual ou real do direito. Desta forma, ele não dá peso suficiente ao princípio da segurança jurídica. Isso se deve ao fato de o não-positivismo exclusivo afirmar que os defeitos morais enfraquecem a validade jurídica em todos os casos. Utilizando "V" para "é válido", e o quantificador universal " $\forall$ ”, Alexy expressa, então, o não-positivismo exclusivo da seguinte maneira:

(4) $\forall x \neg V x$

Visto os fatores que levaram o não-positivismo exclusivo a ser descartado, veremos, então, os motivos pelos quais o não-positivismo super-inclusivo também foi indeferido. $\mathrm{O}$ nãopositivismo super-inclusivo defende que a validade jurídica não é afetada pelos defeitos morais. Isso faz com que este tipo de positivismo não dê peso suficiente à dimensão ideal do direito, ou seja, ao princípio da justiça. Isso é expresso por Alexy da seguinte forma:

(5) $\forall \mathrm{xVx}$

Alexy defende que há apenas um tipo de não-positivismo que possui um equilíbrio onde tanto a dimensão real quanto a dimensão ideal recebem peso adequado, este é o não-positivismo inclusivo. $\mathrm{O}$ não-positivismo inclusivo dá um peso adequado tanto para o princípio da segurança jurídica quanto para o princípio da justiça (Alexy, 2010, p. 6). O não-positivismo inclusivo considera que não é sempre que os defeitos morais afetam a validade jurídica, mas também

\footnotetext{
6 "Kant's combination of the postulate of "[u]nconditional submission" (Kant 1996, 506) to the positive law with the idea of a necessary subjugation of the positive law to non-positive law can be read as a version of super-inclusive nonpositivism (see Alexy 2008a, 288-9;2010, 174). The same applies to the thesis of Aquinas that a tyrannical law is law but "not law simpliciter" or, as John Finnis puts it, "not law in the focal sense of the term "law"" (Finnis 1980, 364).
} 
consideram que igualmente não é nunca que não o fazem. Tendo em vista a fórmula de Radbruch, Alexy declara:

[...] o não-positivismo inclusivo sustenta que os defeitos morais minam a validade jurídica se e somente se o limiar de extrema injustiça é transgredido. Injustiça abaixo desse liminar está incluída no conceito de direito como direito defeituoso, mas válido ${ }^{7}$ (ALEXY, 2012, p. 6, tradução nossa).

Isso é expresso da seguinte forma:

$$
\text { (6) } \neg \forall x \neg V x \& \neg \forall x V x
$$

Ou, ainda, pode ser expresso por meio de quantificadores existenciais:

(6’) $\exists x V x \& \exists x \neg V x$

Alexy destaca, que, aqui, uma segunda tríade de contrariedade é formulada. Esta tríade, segundo ele, representa uma explicação da posição superior esquerda da "tríade necessária" (vista anteriormente), ou seja, $\square$ I, como uma abreviação do não-positivismo:

\section{$\mathrm{O} \quad$ autor}

tríade quantificadora. tríade quantificadora, positivismo inclusivo, expresso segundo a fórmula: extrema injustiça não é direito. O nãopositivismo inclusivo é o que devemos considerar como o objeto do argumento do relativismo.

\section{O não-positivismo inclusivo e o problema da existência}

De acordo com o autor, o argumento do relativismo é um grande desafio para o nãopositivismo inclusivo, o único tipo de não-positivismo defensável. Se não existissem elementos morais necessários, como os direitos humanos e os princípios universais de justiça, então, afirma Alexy, o não-positivismo entraria em colapso por seu próprio peso, pois, não existindo estes elementos morais necessários, então, não se poderia dizer que extrema injustiça existe. A existência pressupõe uma objetividade e elementos morais são objetivos apenas se forem necessários. Alexy faz uma declaração acerca dos elementos morais e sobre a implicação da não existência da extrema injustiça:

\footnotetext{
7 “ $[. .$.$] inclusive non-positivism maintains that moral defects undermine legal validity if and only if the threshold of$ extreme injustice is transgressed. Injustice below this threshold is included in the concept of law as defective but valid law."
} 
ela passaria a ser subjetiva e com poder envolto sob uma máscara de objetividade e racionalidade ${ }^{8}$ (ALEXY, 2012, p. 7, tradução nossa).

A tese que afirma a existência de elementos morais necessários é denominada tese da existência. A verdade do não-positivismo depende diretamente da verdade da tese da existência. Tendo " $\neg \mathrm{P}$ " como suporte para o não-positivismo e "E" como a tese que alega a existência de elementos morais necessários, podemos representar esta relação como representado a seguir:

$$
\text { (7) } \neg \mathrm{P} \rightarrow \mathrm{E}
$$

Podemos afirmar, segundo Alexy, que a veracidade da tese da existência (E) é uma condição necessária para o não-positivismo $(\neg \mathrm{P})$ e, esta, implica a proposição de que a negação da tese da existência $(\neg \mathrm{E})$ é uma condição suficiente para afirmar a verdade do positivismo (P). Esta relação é representada desta maneira:

$$
\text { (8) } \neg \mathrm{E} \rightarrow \mathrm{P}
$$

De acordo com o que foi analisado, comprovando-se que a tese da existência é falsa, o nãopositivismo também não é verdadeiro, o que faz com que prevaleça o positivismo e, então, neste caso, o argumento de Kelsen se confirma. Porém, se a tese da existência for considerada verdadeira, não é o caso de concluir que o não-positivismo prevalece. Isso ocorre pelo fato de a verdade da tese da existência ser uma condição necessária, não uma condição suficiente para que se comprove a verdade do não-positivismo. Portanto, tem-se que o problema da existência é um dos principais problemas do não-positivismo, uma vez que a verdade da tese da existência é uma condição necessária para a verdade do não-positivismo, porém, suficiente apenas para a possibilidade do não-positivismo.

\section{Direitos humanos como elementos morais}

A principal discussão no positivismo pode ser resumidamente colocada como a discussão sobre se os elementos morais devem ou não ser incluídos no conceito de direito, e se elementos morais são necessariamente relacionados com a natureza do direito. Surge, então, o questionamento: por que estes elementos morais devem contar como direitos humanos?'. Uma importante razão para tal está relacionada a outro importante elemento moral que possui uma relação com os direitos humanos: a "noção de justiça". Direitos humanos e a "noção de justiça" possuem uma relação que pode ser apresentada como: toda violação dos direitos humanos é injusta, porém, nem toda injustiça é uma violação de direitos humanos. Alexy declara: "Se isso for verdade,

\footnotetext{
8 "If there existed no extreme injustice, the Radbruch formula would be nothing more than an empowerment to those who decide on the validity of law to declare, should they choose, duly issued and socially efficient norms that do not correspond to their factually held moral ideas, preferences, or ideologies to be invalid. The Radbruch formula would not only lose its sense. Still worse, it would turn out to be subjectivity and power shrouded under a mask of objectivity and rationality."

${ }^{9}$ Não adentraremos neste assunto no presente artigo. Sobre isto, no entanto, o autor escreve o seguinte: "In discussing the argument from relativism in The Argument from Injustice, I confined myself to the claim that a proposition such as: The physical and material destruction of a minority of the population on grounds of race is injustice in the extreme. (Alexy 2002, 54) is rationally justifiable. I did not, however, justify this claim to justifiability. Instead of a justification I referred - apart from discourse theory as taken up in A Theory of Legal Argumentation (Alexy 1989a, 33-208) - to an article in which I attempted, for the first time, to offer a justification of human rights (Alexy 1989b, 167-83). This is something I developed further in the following years, especially in the articles "Discourse Theory and Human Rights" (Alexy 1996, 209-35) and "Menschenrechte ohne Metaphysik?" (Alexy 2004, 15-24). In what follows I consider whether arguments along these lines suffice to establish the existence of human rights and whether the existence of human rights, established in this way, serves to refute the argument from relativism." (ALEXY, 2012, p. $8-9)$.
} 
os direitos humanos representam o núcleo da justiça, ao passo que a justiça compreende mais que direitos humanos. Isso pode ser chamado de 'tese central"' (ALEXY, 2012, p. 9, tradução nossa).

Há uma tese diferente da tese central que afirma que a justiça e os direitos humanos são coextensivos. A dinâmica desta coextensividade se dá de maneira que toda violação dos direitos humanos é considerada injusta, e toda injustiça é considerada uma violação dos direitos humanos. Esta tese é denominada de tese da equivalência. Considerando o que foi proposto ser trabalhado aqui, não é relevante saber qual tese, a tese central ou a tese da equivalência, é verdadeira. Seguindo a dinâmica descrita acima, tem-se que, na violação de direitos humanos há simultaneamente uma violação à justiça e, desta forma, escreve Alexy (ALEXY, 2012, p. 9), a existência de direitos humanos implica a existência de princípios de justiça. Desta maneira, existindo direitos humanos, tanto eles quanto a justiça constituem os elementos morais. É importante ressaltar que, para Alexy, não apenas os direitos humanos e a justiça constituem o que podemos considerar de domínio do que denominamos ser a moral. Acrescenta-se a isso um terceiro elemento o qual o autor se refere como "as concepções individuais e coletivas de bem" (ALEXY, 2012, p. 9, tradução nossa). Os direitos humanos são normas que possuem prioridade frente a todas as outras normas. E, se são justificáveis os direitos humanos, sua reivindicação por prioridade frente às demais normas morais também é, então, justificável. Desta forma, Alexy afirma que:

[...] 'identidade como um elemento moral pode realmente influenciar a concepção de justiça' (Alexy, 1999, p. 379), mas não pode restringir o papel dos direitos humanos e da justiça na discussão do argumento da relatividade ${ }^{10}$ (ALEXY, 2012, p. 9-10, tradução nossa).

\section{O conceito de direitos humanos em Alexy}

Direitos humanos são conceituados por Alexy como: primeiramente, direitos morais; em segundo, direitos universais; em terceiro, direitos fundamentais; em quarto, direitos abstratos e; em quinto, possuem prioridade frente às demais normas (ALEXY, 2012, p. 10). Sobre este conceito dos direitos humanos, Alexy conclui:

Aqui, o primeiro elemento definidor é de especial importância. Segundo ele, os direitos humanos são direitos morais. Direitos existem se forem válidos. Agora, os direitos morais são válidos se e somente se eles são justificáveis. Por essa razão, a existência de direitos humanos quanto direitos morais depende, tão somente, de sua justificação (ALEXY, 2012, p. 10 tradução nossa). ${ }^{11}$

\section{A justificação dos direitos humanos}

Existem diversas teorias sobre a justificação dos direitos humanos, assim como teorias sobre a justificação das normas morais de um modo geral. Essas teorias são classificadas de diferentes maneiras. Geralmente, as teorias são divididas em dois grupos: um grupo das teorias que negam a possibilidade de qualquer justificação dos direitos humanos, denominado de ceticismo, e outro grupo que engloba as teorias que alegam algum tipo de justificação possível, denominado

\footnotetext{
10 “[...] identity as a moral element may indeed influence the conception of justice (Alexy 1999, 379), but it cannot restrict the role of human rights and justice in the discussion of the argument from relativity."

11 "Here the first defining element is of special importance. According to it, human rights are moral rights. Rights exist if they are valid. Now moral rights are valid if and only if they are justifiable. For this reason, the existence of human rights qua moral rights depends on their justifiability, and on that alone."
} 
não-ceticismo. O ceticismo possui origem no emotivismo, decisionismo, subjetivismo, relativismo, naturalismo ou desconstrutivismo. Já o não-ceticismo pode até incluir alguns elementos citados como pertencentes ao ceticismo (emotivismo, decisionismo, subjetivismo, relativismo, naturalismo ou desconstrutivismo), porém, conforme afirma Alexy, o não-ceticismo:

[...] insiste em que haja a possibilidade de dar razões aos direitos humanos, que reivindicam objetividade, correção ou verdade. O não-positivismo pressupõe que alguma versão do não-ceticismo pode ser justificada ${ }^{12}$ (ALEXY, 2012, p. 10, tradução nossa).

Isto posto, Alexy realiza uma análise na qual tenta justificar os direitos humanos em oito abordagens não-céticas. Estas abordagens compreendem:

(i) a religiosa,

(ii) a intuicionista,

(iii) a consensual,

(iv) a biológica,

(v) a instrumental,

(vi) a cultural,

(vii) a explicativa,

(viii) a existencial.

Segundo o autor, as seis primeiras abordagens apresentam mais defeitos do que pontos fortes, e, portanto, Alexy dedica-se apenas a discutir a sétima e a oitava abordagem que serão trabalhados a seguir.

\section{O argumento explicativo de Alexy}

Alexy considera que a justificação dos direitos humanos consiste em explicar o que é necessariamente implícito na prática humana e, sendo assim, a justificação dos direitos humanos é, então, explicativa (ALEXY, 2012, p. 11). Este argumento explicativo trabalha tornando explícito o que é implícito na prática humana. $\mathrm{O}$ argumento possui como principal referência a filosofia transcendental de Immanuel Kant. Alexy acrescenta que esta prática humana, citada acima, é a prática de afirmar, e este "afirmar" está perguntando e discutindo, e através desta dinâmica, a justificação apresenta um caráter teórico-discursivo.

Para Alexy, a prática discursiva pressupõe, necessariamente, "regras do discurso que expressam as ideias de liberdade e igualdade" (ALEXY, 1996, p. 213). Estas ideias de liberdade e igualdade formam o que podemos chamar de base dos direitos humanos. O autor declara:

Reconhecer um outro indivíduo como livre e igual é reconhecê-lo como autônomo. Reconhecê-lo como autônomo é reconhecê-lo como uma pessoa. Reconhecê-lo como uma pessoa é atribuir-lhe dignidade. A atribuição de dignidade a alguém é reconhecer os seus direitos humanos. Com isso, pode-se pensar que uma justificação dos direitos humanos fora alcançada ${ }^{13}$ (ALEXY, 2012, p. 11, tradução nossa).

\footnotetext{
12 [...] insists that there be a possibility of giving reasons for human rights, reasons that lay claim objectivity, correctness, or truth. Non-positivism presupposes that some version of non-scepticism can be justified.

13، To recognize another individual as free and equal is to recognize him as autonomous. To recognize him as autonomous is to recognize him as a person. To recognize him as a person is to attribute dignity to him. Attributing dignity to someone is, however, to recognize his human rights. With this, one might think, a justification of human rights has been achieved."
} 
Da maneira descrita acima, Alexy demonstra ser possível justificar os direitos humanos através do argumento explicativo, porém, esta justificação apresenta falhas que serão apresentadas e trabalhadas a seguir ${ }^{14}$.

\section{O argumento existencial de Alexy}

Como afirmado anteriormente, o argumento explicativo é um argumento insuficiente, pois possui alguns defeitos. O primeiro defeito repousa no fato de o argumento explicativo necessitar de regras discursivas, porém, este defeito pode ser contornável ao se evitar qualquer participação na prática de afirmar, perguntar e discutir. No entanto, isso se torna inviável, pois, jamais afirmar coisa alguma, jamais fazer qualquer tipo de questionamento, jamais dar qualquer razão, seria não realizar o que podemos considerar de natureza dos seres humanos enquanto criaturas discursivas. O que poderia ser feito para amenizar esta "solução" seria abandonar o discurso apenas parcialmente. Esta solução também resolve parte do segundo defeito apresentado pelo argumento explicativo. O segundo defeito do argumento explicativo concentra-se nas diferenças entre discurso e ação e nas diferenças das capacidades e interesses. Alexy afirma existir um problema denominado "problema de interesse" (ALEXY, 2012, p. 12) o qual afirma que possuir capacidades discursivas não implica um interesse em utilizá-las. Este problema do interesse está relacionado à dimensão do discurso e à dimensão da ação. Há uma diferenciação entre a vida real e a mera conversa. Para o autor, os direitos humanos, agora, também dizem respeito à ação e não apenas ao discurso. Sobre o interesse em fazer uso das capacidades, temos: o "fraco interesse na correção" (ALEXY, 2012, p. 12), que se aplica ao interesse de usar as capacidades discursivas apenas na esfera argumentativa, e o "forte interesse na correção" (ALEXY, 2012, p. 12), que diz respeito ao interesse de fazer uso das capacidades não apenas no âmbito da argumentação, mas também no âmbito da ação. O forte interesse na correção traduz-se como considerar seriamente as implicações discursivas na vida real, isto é, levar direitos humanos a sério. Isto posto, Alexy compreende que o interesse na correção possibilita chegar ao objetivo da justificação dos direitos humanos.

Esta justificação de maneira alguma pode ser considerada infundada ou leviana. Ela é devidamente endossada, isto é, comprovada através de explicação, um recurso necessariamente ligado aos seres humanos, ou ainda, como considera Alexy, uma possibilidade necessária. $\mathrm{O}$ argumento existencial está intrinsecamente conectado ao argumento explicativo. Alexy denomina esta ligação de justificação explicativo-existencial.

$\mathrm{O}$ argumento explicativo expressa esta capacidade inerente à natureza dos seres humanos, isto é, a capacidade discursiva. Alexy caracteriza esta natureza discursiva como "a dimensão ideal do indivíduo". Baseia-se em Soren Kierkegaard que entende que esta natureza (a natureza discursiva) não pode ser adquirida fora do ser humano, pois, representa ele próprio e, só pode vir de dentro do próprio ser humano (KIERKEGAARD apud ALEXY, 2012, p. 12). Alexy afirma:

O endosso da dimensão ideal, que o indivíduo encontra em si mesmo, conecta elementos subjetivos com objetivos. A dimensão objetiva é composta por dois elementos: primeiro as possibilidades discursivas necessárias e, segundo, seu caráter ideal. Isso é a priori requerido por Kelsen (1967, p. 65). A dimensão subjetiva consiste na decisão existencial que transforma essas possibilidades ideais em realidade. Isso significa que os direitos humanos só podem ser justificados por uma conexão de elementos objetivos e subjetivos.

\footnotetext{
${ }^{14}$ Sobre a questão da dignidade humana, seu caráter absoluto, seus limites seja na condição de princípio ou direito fundamental, conferir: PADILHA; BERTONCINI, 2016.
} 
Essa conexão pode ser caracterizada como uma dialética objetiva e subjetiva ${ }^{15}$ (ALEXY, 2012, p. 12, tradução nossa).

O argumento explicativo-existencial pode ser qualificado como um argumento que justifica os direitos humanos, mesmo que ele não constitua uma justificação puramente objetiva, pois, segundo Alexy:

Pode-se objetar que a justificação só pode ser objetiva ou subjetiva, e não, por assim dizer, 'meio objetiva', e que qualquer contaminação com elementos subjetivos elimina completamente a objetividade. A resposta para isso é que a objetividade ligada com a subjetividade é, com certeza, menos que pura objetividade, mas também é mais do que pura subjetividade ${ }^{16}$ (ALEXY, 2012, p. 12, tradução nossa).

$\mathrm{O}$ argumento explicativo-existencial, segundo Alexy, fornece boas razões para os direitos humanos, pois, constitui-se uma justificação combinada devido a seus elementos objetivos e subjetivos que compõem a objetividade ligada a subjetividade. Desta forma, este argumento é suficiente para justificar os direitos humanos. Esta justificação, segundo Alexy (ALEXY, 2012, p. 12), estabelece a validade dos direitos humanos enquanto direitos morais, e, desta maneira, fica estabelecido que, de fato, existem direitos humanos. Existindo direitos humanos, significa que estes podem ser violados. Havendo a possibilidade de os direitos humanos serem violados eles podem, então, enquanto direitos abstratos, serem violados em maior ou menor grau ou num grau extremo. Ao existir a possibilidade dos direitos humanos poderem ser violados em um grau extremo, significa, conclui Alexy, que a fórmula de Radbruch é aplicável (ALEXY, 2012, p. 13). E, sendo tudo isso verdade, como foi demonstrado até aqui, Alexy acredita que o argumento do relativismo é refutado. Com isso, segundo o autor, simultaneamente, temos que ocorre a refutação do próprio positivismo.

\section{HART E OS CINCO TIPOS DISTINTOS DE POSITIVISMO}

Alexy tem se dedicado nestes últimos anos a desenvolver um trabalho que visa fundamentar a moral. Seu trabalho, desde já de grande importância, trás consigo a união dos direitos humanos e do Direito. Hart, escolhido para contrapor a ideia de Alexy acerca da refutação do positivismo, é um importante positivista do século XX e, atualmente, é citado como uma importante referência nos textos sobre positivismo. Sendo assim, sua definição possui valor para o estudo do conceito de positivismo.

$\mathrm{O}$ argumento de Alexy demonstra que ao ser comprovada a existência de direitos humanos e, tendo sido provado que estes podem ser violados, então, isto comprovaria que a fórmula de

\footnotetext{
15“"The endorsement of the ideal dimension that the individual finds in himself connects objective with subjective elements. The objective dimension consists of two elements, first the necessary discursive possibilities, and second, their ideal character. This is the a priori required by Kelsen $(1967,65)$. The subjective dimension consists of the existential decision that transforms these ideal possibilities into reality. This means that human rights can only be justified by a connection of objective and subjective elements. This connection can be characterized as a dialectic of the objective and the subjective."

16 "It might be objected that a justification can only be either objective or subjective, and not, so to speak, 'halfobjective,' and that any contamination with subjective elements eliminates objectivity altogether. The reply to this is that objectivity connected with subjectivity is, to be sure, less than pure objectivity, but it is also more than pure subjectivity."
} 
Radbruch é aplicável e, consequentemente, o argumento do relativismo é refutado e, por conseguinte, o positivismo também o teria sido. Nesta parte do artigo, daremos início a apresentação da abordagem de Hart, onde ele elenca cinco tipos de positivismo, o que levantará nossa hipótese central de que, de acordo com estes cinco tipos de positivismo e suas respectivas características, poder-se-ia querer questionar a refutação de Alexy.

\section{O direito como ele é e como deveria ser}

Jeremy Bentham e John Austin, positivistas que tiveram grandes contribuições na área dos problemas jurídicos e sociais, acreditavam que era necessário que se fizesse uma diferenciação entre o direito como ele é e o direito como ele deve ser. A busca por esta diferenciação entre direito e moral fez com que ambos os autores condenassem os pensadores do direito natural, pois, para estes teóricos, os defensores do direito natural teriam obscurecido esta distinção, e desta forma, ocultado uma distinção, considerada por eles, de uma importância fundamental. Porém, Hart considera que, atualmente, a distinção entre direito e moral pode ser considerada como superficial e equivocada. Ele afirma que alguns críticos crêem que esta distinção acaba por tornar-se um empecilho no que se refere a identificação da verdadeira natureza do Direito e suas raízes na vida social. Outros, acrescenta Hart, consideram ainda que tal distinção seria intelectualmente enganosa, podendo gerar um desrespeito ao direito e até mesmo ser capaz de diminuir a resistência à tirania estatal ou ao absolutismo (HART. 2010, p. 61).

Hart ressalta que ao enfatizarem a distinção de como o direito é e como ele deveria ser, Bentham e Austin consideravam algumas leis específicas, "cujos sentidos estavam claros e, assim, não em disputa, e estavam preocupados em sustentar que tais leis, mesmo se moralmente ultrajantes, ainda eram leis" (HART. 2010, p. 61). Hart afirma que é necessário que haja uma compreensão do fato de que ao defenderem uma terminologia diferente para o que o direito é e o que ele deveria ser, Bentham, Austin e os demais utilitaristas, também estavam sugerindo uma separação geral (general cleavage) entre Direito e moral, o que culminou em um obscurecimento do fato de que, em outros momentos, existe efetivamente um ponto de contato entre o Direito e a moral. Hart, então, afirma (claim) haver uma conexão (connection) entre Direito e moral. Isso pode ser verificado, segundo Hart, ao se examinar o modo como as leis são interpretadas e aplicadas em casos concretos. Hart afirma, ainda, que esta conexão surge mais uma vez se:

[...] ampliamos nosso ponto de vista e perguntamos, não se cada norma jurídica particular deve satisfazer um mínimo moral para ser uma lei, mas se um sistema de normas que, como um todo, deixa de fazê-lo, pode ser um sistema jurídico (HART. 2010, p. 61).

Hart destaca que, conjuntamente com esta visão que defende a distinção entre o Direito e a moral, os utilitaristas defendiam outras duas teorias. A primeira delas é teoria de que um estudo puramente analítico de conceitos jurídicos, um estudo do sentido (meaning) do vocabulário próprio do Direito, seria tão fundamental para assimilar a natureza do Direito quanto os estudos sociológicos ou históricos. A outra teoria defendida pelos utilitaristas é a teoria imperativa da lei, teoria essa que defende que a lei é, basicamente, um comando.

Estas três teorias compõem o que conhecemos como a tradição utilitarista na teoria do Direito. Porém, afirma Hart, estas três doutrinas, apesar de serem defendidas todas pelos utilitaristas, são três doutrinas distintas. Hart salienta que é possível defender duas destas teorias e

ir contra a terceira sem que as demais sejam invalidadas. É possível defender, por exemplo, a separação entre Direito e moral, apoiar os estudos analíticos do sentido de conceitos jurídicos e, ao 
mesmo tempo, desacreditar da doutrina que afirma que a lei é essencialmente um comando. Hart aponta que ocorre uma interpretação errônea quanto a uma falsa conexão necessária entre estas três doutrinas. Muitos acreditam que provando que uma destas três teorias é falsa, então, as outras duas teorias também teriam sido falseadas. E, esta interpretação errônea gera uma grande confusão (confusion) na crítica à separação entre o Direito e a moral.

O termo positivismo é utilizado para designar cada uma destas teorias. Essa banalização do uso do termo positivismo deu origem a um grande equívoco e isso veio a tornar-se a mais um problema existente na crítica à separação entre o Direito e a moral. Esta confusão sobre o conceito de positivismo acarretou em diversas críticas não procedentes, que afirmavam ter encontrado uma maneira de falsear o positivismo ao provar que uma destas três teorias era falsa. Para esclarecer, então, o conceito de positivismo, Hart fez a seguinte declaração, afirmando haver cinco ou mais significados de positivismo na teoria contemporânea do direito. São eles:

1. A afirmação de que leis são comandos de seres humanos;

2. A afirmação de que não há conexão necessária entre direito e moral ou entre o direito como ele é e como deve ser;

3. A afirmação de que a análise (ou estudo do significado) dos conceitos jurídicos (a) vale a pena perseguir e (b) deve ser distinguida da investigação histórica sobre as causas e origens das leis, das investigações sociológicas sobre a relação do direito com outros fenômenos sociais, "funções", ou de outro tipo;

4. A afirmação de que um sistema jurídico é um "sistema lógico fechado" em que decisões jurídicas corretas podem ser deduzidas por meios lógicos a partir de regras jurídicas pré-determinadas sem referência a fins sociais, políticas públicas (policies), padrões morais;

5. A afirmação de que o julgamento moral não pode ser estabelecido ou defendido, como declarações de fato podem, por argumento racional, evidência ou prova ("não cognitivismo" em ética). (HART. 2010, p. 62)

De acordo com esta declaração, cada uma destas características apresentadas demonstra as maneiras que o positivismo é rotulado, sendo que, uma maneira não depende da outra para afirmar a veracidade do conceito e características do positivismo, ou seja, como foi analisado anteriormente, uma destas características pode ser considerada falsa em um determinado contexto, porém, isto não implicará que o positivismo em si estará sendo falseado.

Segundo a afirmação de que não há conexão necessária entre Direito e moral ou entre o Direito como ele é e como deve ser, significa que não há uma conexão necessária entre Direito e moral. Porém, de modo algum é dito que não há conexão entre Direito e moral.

\section{CONCLUSÃO}

Jeremy Waldron em Law and Disagreement, afirma a necessidade de se utilizar as mesmas premissas para que possa haver argumentação (WALDRON, 2001). Waldron escreve que em uma discussão entre um nietzcheano e um kantiano não pode haver método, pois, ambos discorrem baseando-se em premissas distintas, o que gera argumentações baseadas em premissas válidas sempre apenas para um dos dois discursos. Podemos dizer que o mesmo ocorre entre Alexy e Hart.

Alexy, de fato, refuta o positivismo em seu artigo Law, Morality, and the Existence of Human Rights, porém, o positivismo por ele refutado é um positivismo segundo o qual o Direito e a moral não possuem nenhum tipo de contato. Há aqui, então, o que parece ser um problema no que se refere às premissas utilizadas por Alexy. Em sua obra, Hart elenca cinco características 
apresentadas pelo positivismo. Dentre estas cinco, uma delas se destaca ocupando um importante papel neste trabalho: a aafirmação de que não há conexão necessária entre Direito e moral ou entre o direito como ele é e como deve ser. Segundo está afirmação, Alexy teria, sim, contribuído de maneira significativa para a filosofia do Direito e para a teoria do Direito, uma vez que, ao justificar os direitos humanos, Alexy teria conseguido fundamentar a moral, fortalecendo o nãopositivismo e apresentando um valor moral absoluto, o que exige uma boa reflexão, pois, como um valor moral absoluto pode não estar conectado ao Direito? Entretanto, considerando a obra de Hart, é possível ver que o conceito de positivismo abarca diversas características e que considerá-lo, simplesmente, do modo como Alexy o fez, estaria ignorando detalhes fundamentais que impediriam a refutação proposta pelo prórpio autor. Deomonstramos portanto, os limites da teoria de Alexy, concluindo que é possível, sim, que Alexy tenha conseguido refutar um tipo específico de positivismo, mas não o positivismo jurídico.

\section{REFERÊNCIAS}

ALEXY, Robert. Law, Morality, and the Existence of Human Rights. In: Ratio Juris, vol. 25, n. 1, p. 2-14, 2012.

ALEXY, Robert. The Dual Nature of Law. In: Ratio Juris, v. 23, p. 167-82, 2010.

ALEXY, Robert. The Argument from Injustice.A Reply to Legal Positivism. Trans.: Bonnie Litschewski Paulson and Stanley L. Paulson. Oxford: Clarendon. 2002.

ALEXY, Robert. A Theory of Constitutional Rights. Trans.: Julian Rivers. Oxford: Clarendon Press, 2002.

ALEXY, Robert. Discourse Theory and Human Rights. In: Ratio Juris, v. 9, p. 209-35, 1996.

ALEXY, Robert. A Theory of Legal Argumentation. Trans.: Ruth Adler and Neil MacCormick. Oxford: Clarendon, 1989a.

ALEXY, Robert. On Necessary Relations between Law and Morality. In: Ratio Juris, v. 2, p. 16783, 1989.

AUSTIN, John. Lectures on Jurisprudence. The Lawbook Exchange, Ltd., 1885.

AUSTIN, John. The Province of Jurisprudence Determined. Cambridge University Press, 1995.

BARZOTTO, Luis Fernando. O Positivismo Jurídico Contemporâneo: uma introdução a Kelsen, Ross e Hart. Unisinos, 1999.

BENTHAN, Jeremy. An Introduction to the Principles of Morals and Legislation. J. H. Burns and H. L. Hart (Ed.). Oxford University Press, NY, 1996.

CARVALHO, Juliana Brina Côrrea Lima de. Sobre os limites da argumentação jurídica: a desconstrução do ativismo judicial fundado na ponderação de princípios e a reinvenção da 
legitimidade jurídica nos pensamentos de Jürgen Habermas e Chantal Moufee. In: Revista de Direito Brasileira, v. 2, n. 2, p. 47-94, jan-jun, 2012.

CHAO, Benny. Hart on Natural Rights. In: Civilitas, p. 1-14, 2011.

COLEMAN, Jules (Ed.). Hart's Postscript: Essays on the Postscript to the 'Concept of Law'. Oxford University Press, 2001.

DARWALL, Stephen; GIBARD, Allan; RAILTON, Peter. Metaética: algumas tendências. Organização: Darlei Dall Agnol. Tradução: Janyne Sattler. Florianópolis: Ed. da UFSC, 2013.

DUXBURY, Neil. English jurisprudence between Austin and Hart. In: Virginia Law Review, v. 91, n. 1.p. 1-91, 2005.

HABERMAS, Jürgen. A Ética da Discussão e a Questão da Verdade. São Paulo, Martins Fontes, 2007.

HABERMAS, Jürgen. Between Facts and Norms. Trans.: William Rehg. Cambridge: Polity. 1996.

HABERMAS, Jürgen. Consciência Moral e Agir Comunicativo. Tradução de Guido de Almeida. Rio de Janeiro: Tempo Brasileiro, 1989.

HART, Herbert. L. A. Ensaios sobre teoria do direito e filosofia. Rio de Janeiro: Elsevier, 2010.

HART, Herbert. L. A. O conceito de direito. Tradução de A. Ribeiro Mendes. São Paulo: Martins Fontes, 2009.

HART, Herbert. L. A. Punishment and responsibility. New York: Oxford University Press, 2008.

HART, Herbert. L. A. The Concept of Law. 2. ed., Oxford: Clarendon Press, 1994.

HART, Herbert. L. A. Direito, liberdade e moralidade. Tradução de Gérson Pereira dos Santos. Porto Alegre, RS: Fabris, 1987.

HART, Herbert. L. A. Essays in Jurisprudence and Philosophy. Clarendon Press, 1983.

HART, Herbert. L. A. Essays on Bentham. Jurisprudence and political theory. Oxford: Clarendon Press, 1982.

HART, Herbert. L. A. Are There Any Natural Rights? In: The Philosophical Review, v. 64, n. 2, p. 175-191, 1975.

HART, Herbert. L. A. The Concept of Law. Oxford: Oxford University Press, 1961.

HART, Herbert. L. A. Positivism and the Separation of Law and Morals. In: Harvard Law Review. N. 71, p. 563-629, 1957. 
KANT, Immanuel. The Metaphysics of Morals. In: Immanuel Kant, Practical Philosophy. Trans. and ed.: Mary J. Gregor. Cambridge: Cambridge University Press, 1996.

KELSEN, Hans. Pure Theory of Law. Trans.: Max Knight. Berkeley and Los Angeles: University of California Press, 1967.

MACCOMICK, Neil. H. L. A. Hart. Tradução de Claúdia Martins. Rio de Janeiro: Elsevier, 2010.

PADILHA, Elisângela; BERTONCINI, Carla. A dignidade da pessoa humana na teoria dos direitos fundamentais de Robert Alexy: uma análise sobre o seu caráter absoluto ou relativo na ordem jurídico-constitucional. In: Revista de Direito Brasileira, v. 13, n. 6, p. 95-110, jan-abr, 2016.

RAZ, Joseph. The Authority of Law. Oxford: Oxford University Press, 2009.

WALDRON, Jeremy. A Dignidade da Legislação. Tradução de Luís Carlos Borges. São Paulo: Martins Fontes, 2003.

WALDRON, Jeremy. Law and Disagreement. Oxford University Press, 2001. 